Nat. Hazards Earth Syst. Sci., 10, 2507-2514, 2010

www.nat-hazards-earth-syst-sci.net/10/2507/2010/

doi:10.5194/nhess-10-2507-2010

(C) Author(s) 2010. CC Attribution 3.0 License.

\title{
Experimental study on the rheological behaviour of debris flow
}

\author{
A. Scotto di Santolo, A. M. Pellegrino, and A. Evangelista \\ Department of Hydraulic, Geotechnical and Environmental Engineering, University of Naples "Federico II", Italy
}

Received: 27 December 2009 - Revised: 29 August 2010 - Accepted: 30 August 2010 - Published: 7 December 2010

\begin{abstract}
A model able to describe all the processes involved in a debris flow can be very complex owing to the sudden changing of the material that turns from solid into liquid state. The two phases of the phenomenon are analysed separately referring to soil mechanics procedures with regard to the trigger phase, and to an equivalent fluid for the postfailure phase. The present paper is devoted to show the experimental results carried out to evaluate the behaviour assumed by a pyroclastic-derived soil during the flow. A traditional fluid tool has been utilized: a standard rotational rheometer equipped with two different geometries. The soils tested belong to deposits that cover the slopes of the Campania region, Italy, often affected by debris flows. The influence of solid concentration $C_{\mathrm{v}}$ and grain size distribution was tested: the soils were destructurated, sieved and mixed with water starting from the in situ porosity. All material mixtures showed a non-Newtonian fluid behaviour with a yield stress $\tau_{y}$ that increases with a solid volumetric concentration and decreases for an increase of sand fraction. The experimental data were fitted with standard model for fluids. A simple relation between $C_{\mathrm{v}}$ and $\tau_{y}$ was obtained. The yield stress seems to be a key parameter for describing and predicting the post-failure behaviour of debris flows. These results suggest that in the field a small change in solid fraction, due to rainfall, will cause a slight decrease of the static yield stress, readily inducing a rapid flow which will stop only when the dynamic yield stress is reached, namely on a much smoother slope. This can explain the in situ observed post-failure behaviour of debris flows, which are able to flow over very long distances even on smooth slopes.
\end{abstract}

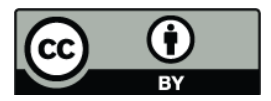

Correspondence to: A. Scotto di Santolo (anscotto@unina.it)

\section{Introduction}

Debris flows represent serious hazards on the slopes of the North-western Campania region (southern Italy). Therefore, the evaluation of constitutive laws for the material involved represents a key requirement for the hazard mitigation. Traditionally, debris flows have been regarded as homogeneous fluids and flow behaviour has been considered to be controlled by the properties of the "matrix", a mixture of fine sediment and water in which coarse particles are dispersed (Costa and Williams, 1984; Johnson, 1984). Existing physical theories to describe flow and depositional process of debris flows are mainly divided into theories which are based on the treatment of the material as one single phase (rheological approaches) (O'Brien and Julien, 1984; Phillips and Davies, 1991; Major and Pierson, 1992; Coussot and Piau, 1994) or as two or more phases (Coulomb mixture approaches) (Savage and Hutter, 1989; Iverson, 1997). The Coulomb mixture approach specifies distinct constitutive equations for the solid phase, the liquid phase and the interaction forces phase. Conversely, using a rheological approach, the bulk mixture behaviour can be characterised by a limited number of parameters, relating shear stress and viscosity to shear rate. The present study focuses on the results obtained by means of a rheological point of view.

\subsection{Debris flow rheology}

Natural debris flows are often classified on the relative concentration of fine and coarse sediments that are used to characterize the main flow regime behaviour (Takahashi, 2007). Above a critical solid concentration $C_{\mathrm{v}}^{*}$, a particle-frictioncollision regime dominates the flow process. Models based on the work of Bagnold (1954) are used to describe the flow behaviour of such mixtures. If the solid concentration is less than the critical one, the flow behaves like a Non-Newtonian

Published by Copernicus Publications on behalf of the European Geosciences Union. 


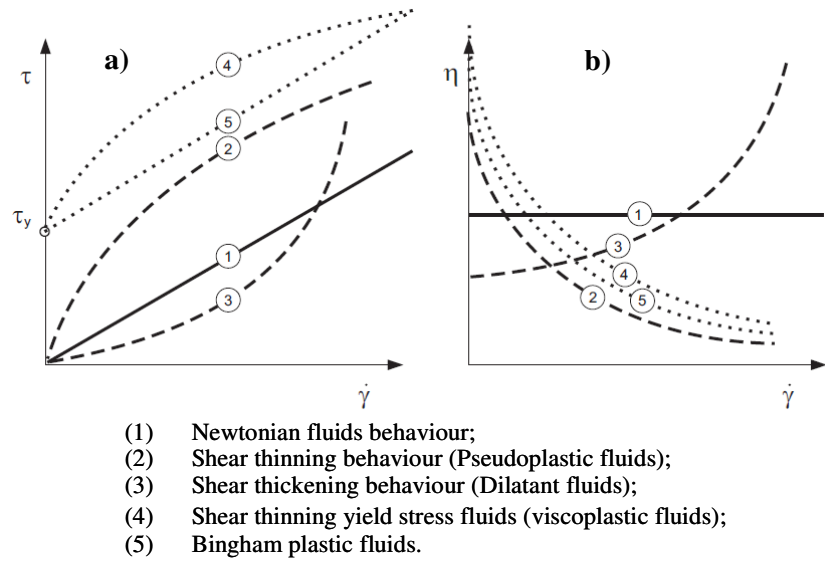

Fig. 1. (a) Flow curves; (b) Viscosity curves.

fluid. They are also called time-independent fluids and are subdivided into several groups (Fig. 1). Generally, the debris flow mixtures behave like viscoplastic fluids, as indicated in curve (4), Fig. 1. It is considered that, for such a fluid, an abrupt change in flow behaviour exists around a given shear stress value, the yield stress $\tau_{y}$, which needs to be overcome before flow takes place. The viscoplastic character of debris flow mixtures has often been reported in literature (O'Brien and Julien, 1984, 1988; Phillips and Davies, 1991; Major and Pierson, 1992; Coussot and Piau, 1995; Contreras and Davies, 2000; Ancey and Jorrot, 2001; Schatzmann, 2005; Kaitna et al., 2007). Phenomenological laws like the Bingham generalized model (or Herschel \& Bulkley model) are usually used to describe the rheological behaviour of such mixtures (Major and Pierson, 1992; Nguyen and Boger, 1992; Coussot, 1997). The mathematical expression can be written as:

$\tau=\tau_{y}+k \cdot \dot{\gamma}^{n}$

In Eq. (1), $\tau_{y}$ is the yield stress, $\dot{\gamma}$ is the shear rate, $k$ is the consistent coefficient $\left[\mathrm{Pa} \mathrm{s}{ }^{n}\right]$ and $n$ is the pseudoplastic index. When the index $n$ is equal to the unity, the Eq. (1) becomes the Bingham model and the coefficient $k$ becomes the Bingham viscosity $\eta_{\mathrm{B}}$ (curve (5) in Fig. 1).

\section{Experimental setup and procedures}

\subsection{Rheometer apparatus}

In order to ensure the validity of rheometrical measurements and to reduce the risk of misinterpretation, the rotational rheometer AR 2000ex (TA Instruments) equipped with two different geometry systems (parallel plates - PP, and vane rotor - VR) has been utilized (Fig. 2). The parallel plates geometry is composed of a lower stationary steel plate and an upper rotational one with a $4 \mathrm{~mm}$ diameter. The distance between two plates (the gap $H$ ) must be at least ten times the

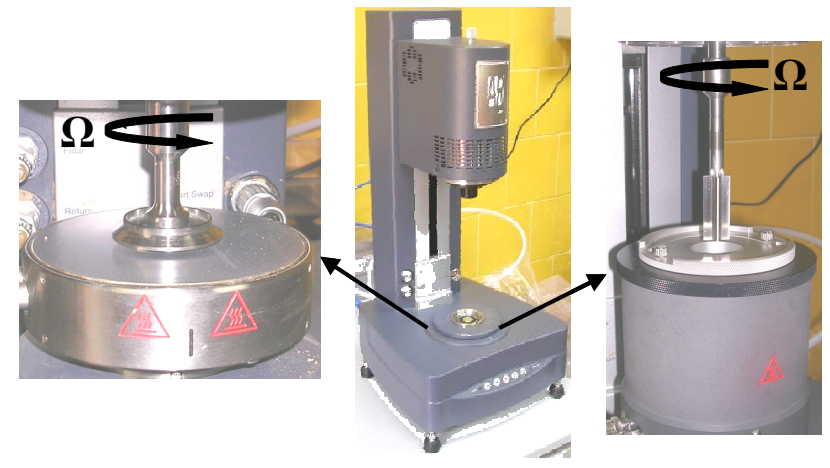

Fig. 2. The rotational rheometer AR 2000ex (TA Instruments) and the two rheometrical system used: parallel plates and vane rotor system.

maximum particles diameter, $d_{\max }$ (Chhabra and Richardson, 1999). Because of the variability in the grain size distribution of the material, the gap has been fixed ( $H$ equal to $1 \mathrm{~mm}$ ) and the maximum diameter has been established according to the previous relation $\left(d_{\max } \leq 0.1 \mathrm{~mm}\right)$. The shear rate and the shear stress are evaluated with the following equations:

$\dot{\gamma}_{R}=\dot{\gamma}(R)=\frac{\Omega \cdot R}{H}$

$\tau\left(\dot{\gamma}_{R}\right)=\frac{3 T}{2 \pi R^{3}}+\frac{\dot{\gamma}_{R}}{2 \pi R^{3}} \cdot \frac{d T}{d \dot{\gamma}_{R}}$

where $R$ is the upper plate radius, $H$ is the gap, $\Omega$ is the rotation velocity (rad/s) and $T$ is the torque (Coussot, 1997).

The vane rotor geometry consists of four thin blades arranged at equal angles around a small cylindrical shaft: the blades radius is $14 \mathrm{~mm}$ and the blades height is $42 \mathrm{~mm}$. It is immersed in the sample contained in a cylindrical cup with $15 \mathrm{~mm}$ in radius. The vane is rotated around its axis at a given rotational speed $\Omega$, and the torque $T$ is measured. During the test the material is trapped in the blades and the shear is achieved around a fictitious cylinder within the mixture. The shear stress and shear rate are:

$\dot{\gamma}=\frac{\Omega \cdot R_{1}}{R_{2}-R_{1}}$

$\tau=\frac{3 \cdot T}{2 \cdot \pi \cdot R_{1}^{2} \cdot L}$

where $R_{1}$ and $R_{2}$ are, respectively, the blades radius and the cup radius, $L$ is the material depth. The Eqs. (4) and (5) are usually applied when the ratio $R_{1} / R_{2}$ is close to the unity (Coussot, 1997); in our case $R_{1} / R_{2}$ is equal to 0.933 . 


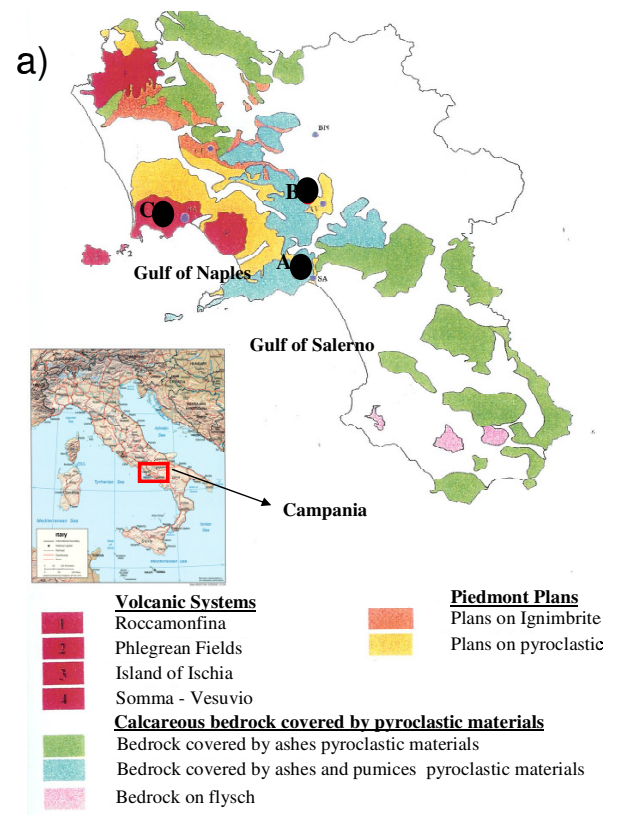

b)

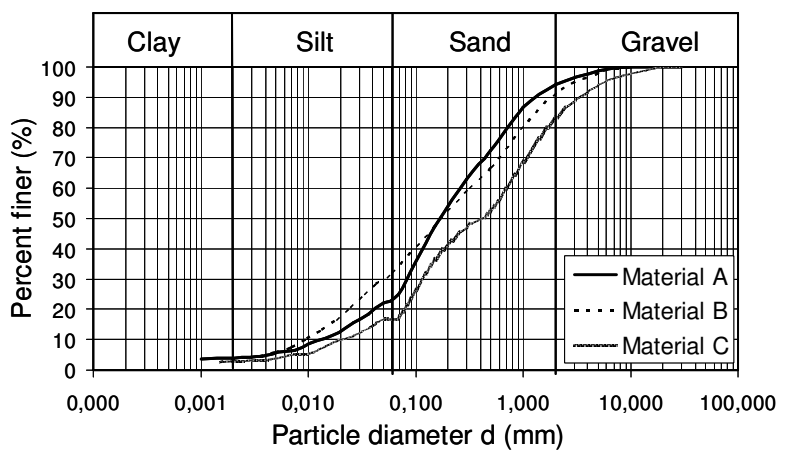

Fig. 3. (a) Location of the studied debris flows and distribution of the main deposits (Modified from di Gennaro et al., 1998); (b) Grain size distribution of the tested debris flow materials.

\subsection{Materials}

The materials tested have been collected from the source area of three debris flows, which are originated in pyroclasticderived terrains, occurred in Campania region (southern Italy), Fig. 3a. Material A has been sampled in Nocera, Salerno (event of March 2005); material B in Monteforte Irpino, Avellino (event of May 1998); material C in Astroni, Naples (event of December 2005). The soil type derived from the most recent deposits produced by the volcanic activity of mount Somma/Vesuvius for materials A and B and by the volcanic activity of the Phlegrean Fields for material C. The grain size distributions of the undisturbed samples are reported in Fig. 3b. Soil A and soil B are sandy silt with a small clay fraction, while soil $\mathrm{C}$ is gravely silty sand. The clay part is slightly plastic though only in the Vesuvian deposits. The gravel part mainly consists of pumices and, to a minor extent, of scoriae and lapilli. The particles are mainly siliceous. Their structure is amorphous and porous; there is a double porosity system inter- and intra-particle (the latter not connected to the surface). Porosity exceeds $70 \%$ for Vesuvian deposits while it is lower for the Phlegrean deposits. The cover is partially saturated; the level of saturation varies according to weather conditions. Mean physical properties are reported in Table $1\left(G_{\mathrm{S}}\right.$ is the specific gravity of soil particles, $\gamma_{\mathrm{d}}$ and $\gamma$ are the dry and total weight of soil per unit volume, respectively, $n$ is the porosity and $S_{r}$ is the degree of saturation). The geotechnical properties of such materials are well documented in literature (e.g. Scotto di Santolo, 2000a, b; Ruopolo, 2006; Papa, 2007; Picarelli et al., 2007). The nature of the substratum underlying the soil is volcanic for material C, and carbonatic for materials A and B (Fig. 3a).

\subsection{Laboratory procedures}

The analysed debris flow mixtures have been tested in ratecontrolled mode at a constant temperature $\left(20 \pm 0.5^{\circ} \mathrm{C}\right)$. The flow curves $(\tau, \dot{\gamma})$ have been determined by applying a successive shear rate level, ranging from 0.014 to 1400 1/s.

For each level of shear rate the duration of the experiment has been imposed long enough to obtain a simple shear steady regime. In order to certify the reproducibility of the experiment, each test has been repeated at least three times and the averaged values of the experimental results have been considered. Due to the geometry dimension of the used rheometer, only the flow curves of fine material with grain sizes smaller than $0.1 \mathrm{~mm}$ have been derived. The experiments have been carried out with mixtures of different water content. The solid volumetric concentration $C_{\mathrm{v}}$, i.e., the ratio of the amount of solids to the total mixture, has been considered. The total solid volumetric concentration $C_{\mathrm{v}}$ is defined as:

$C_{\mathrm{v}}=\frac{V_{\mathrm{s}}}{V_{\mathrm{s}}+V_{\mathrm{w}}}$

where $V_{\mathrm{w}}$ and $V_{\mathrm{s}}$ are, respectively, the volumes of water and solid in the sample. In order to consider a significant range of the sediment concentration for the material tested, mixtures with $C_{\mathrm{v}}$ changing from $20 \%$ to $40 \%$ have been prepared. These values correspond to the variation of porosity in situ ( $n$ ranging from $60 \div 80 \%$ ). Two grain size distributions were analysed for each material: the first with a maximum particle diameter equal to $0.1 \mathrm{~mm}$, and the second with a maximum diameter equal to $0.5 \mathrm{~mm}$, respectively, defined 
Table 1. Main physical properties of the tested debris flow materials.

\begin{tabular}{lccccccc}
\hline Debris flow & Substratum & Material & $\begin{array}{c}G_{\mathrm{S}} \\
(1)\end{array}$ & $\begin{array}{c}\gamma_{\mathrm{d}} \\
\left(\mathrm{kN} / \mathrm{m}^{3}\right)\end{array}$ & $\begin{array}{c}\gamma \\
\left(\mathrm{kN} / \mathrm{m}^{3}\right)\end{array}$ & $\begin{array}{c}n \\
(1)\end{array}$ & $\begin{array}{c}S_{r} \\
(1)\end{array}$ \\
\hline Nocera & Carbonatic & $\mathrm{A}$ & 2.62 & 9.08 & 11.35 & 0.66 & 0.35 \\
Monteforte Irpino & Carbonatic & $\mathrm{B}$ & 2.57 & 7.11 & 12.11 & 0.71 & 0.71 \\
Astroni & Pyroclastic & $\mathrm{C}$ & 2.54 & 8.99 & 9.84 & 0.67 & 0.24 \\
\hline
\end{tabular}

Table 2. Experimental program.

\begin{tabular}{|c|c|c|c|c|c|c|}
\hline \multirow[t]{2}{*}{$\#$} & \multirow[t]{2}{*}{ Material } & \multirow[t]{2}{*}{ Mixture } & \multirow[t]{2}{*}{ Test } & \multirow[t]{2}{*}{$C_{\mathrm{v}}$} & \multicolumn{2}{|c|}{ Geometry system } \\
\hline & & & & & Parallel plate & Vane rotor \\
\hline 1 & \multirow{6}{*}{ A } & \multirow{3}{*}{ FP } & A-FP-20 & 20 & A-FP-20-PP & A-FP-20-VR \\
\hline 2 & & & A-FP-30 & 30 & A-FP-30-PP & \\
\hline 3 & & & A-FP-40 & 40 & A-FP-40-PP & \\
\hline 4 & & \multirow{3}{*}{ LP } & A-LP-20 & 20 & A-LP-20-PP & A-LP-20-VR \\
\hline 5 & & & A-LP-30 & 30 & A-LP-30-PP & \\
\hline 6 & & & A-LP-40 & 40 & A-LP-40-PP & \\
\hline 7 & \multirow{6}{*}{ B } & \multirow{3}{*}{ FP } & B-FP-20 & 20 & B-FP-20-PP & B-FP-20-VR \\
\hline 8 & & & B-FP-30 & 30 & B-FP-30-PP & B-FP-30-VR \\
\hline 9 & & & B-FP-40 & 40 & B-FP-40-PP & B-FP-40-VR \\
\hline 10 & & \multirow{3}{*}{ LP } & B-LP-20 & 20 & B-LP-20-PP & B-LP-20-VR \\
\hline 11 & & & B-LP-30 & 30 & B-LP-30-PP & B-LP-30-VR \\
\hline 12 & & & B-LP-40 & 40 & B-LP-40-PP & B-LP-40-VR \\
\hline 13 & \multirow{6}{*}{$\mathrm{C}$} & \multirow{3}{*}{ FP } & C-FP-20 & 20 & & C-FP-20-VR \\
\hline 14 & & & C-FP-30 & 30 & & C-FP-30-VR \\
\hline 15 & & & C-FP-40 & 40 & & C-FP-40-VR \\
\hline 16 & & \multirow{3}{*}{ LP } & C-LP-20 & & & \\
\hline 17 & & & C-LP-30 & & & \\
\hline 18 & & & C-LP-40 & & & \\
\hline
\end{tabular}

(FP maximum diameter $0.1 \mathrm{~mm}$; LP maximum diameter $0.5 \mathrm{~mm} ;-=$ not investigated.)

fine (FP) and coarse (LP) in the following. The experimental programme performed is shown in Table 2.

\section{Experimental results}

\subsection{Preliminary evaluations}

The choice of the measurement geometry depends on the expected rheological properties of the mixture. Because the rheological properties are unknown a priori, preliminary measurements are absolutely necessary.

Disturbing effects due to material properties and rheometrical geometry features could lead to erroneous data interpretation (Major and Pierson, 1992; Coussot and Piau, 1995; Coussot, 1997; Kaitna et al., 2007). Depending on the geometry apparatus, shear conditions (related to samples volume) and disturbing effects (related to geometry features and fluid types) change in a different way. Data obtained by dif- ferent facilities should be in agreement only if the material tested has been homogeneously sheared as predicted by theory (Major and Pierson, 1992; Coussot, 1997).

In order to understand how the geometry system influences the experimental results, preliminary tests on a typical Newtonian fluid ( $\tau=\eta \cdot \dot{\gamma}$ in which $\eta$ is the viscosity), liquid paraffin on sale with $\eta$ equal to $0.01 \mathrm{~Pa}$ s, have been carried out with parallel plates and vane rotor. Figure 4 reports the flow curves of the liquid paraffin obtained using the mentioned geometries. A quantitative difference, between the experimental results obtained using the parallel plates system and the experimental data obtained using the vane rotor system, has always been noted. Comparing the theoretical and the measured viscosity values, an overestimate of the rheological parameters has been observed when the parallel plates geometry has been used. A scale factor from the results obtained with the parallel plates system to the results obtained with the vane rotor system has been evaluated, by considering the Newtonian behaviour of the liquid paraffin. 

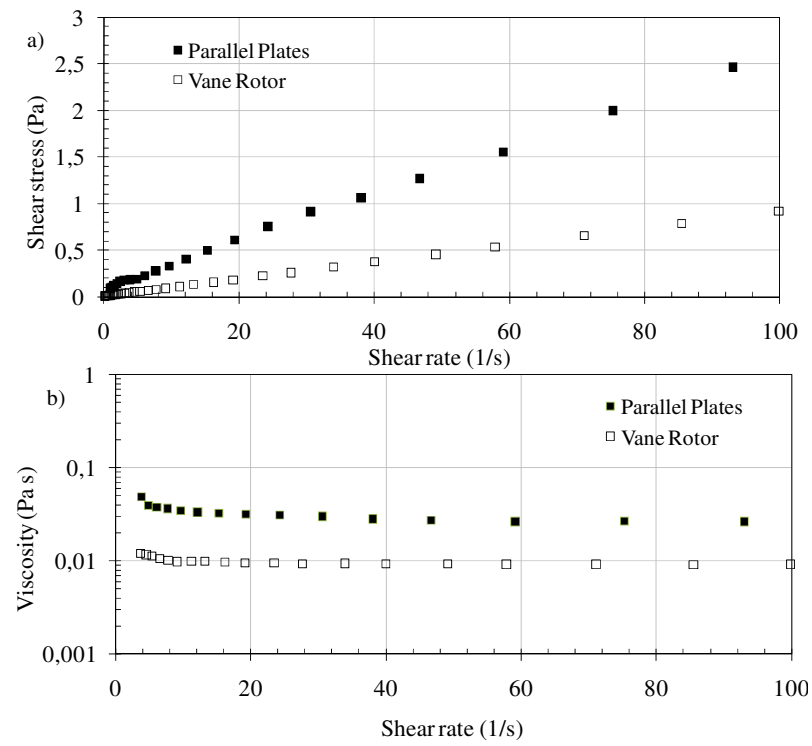

Fig. 4. Liquid paraffin on sale. Comparison of parallel plates results and vane rotor results.

For a Non-Newtonian fluid, like the mixtures tested, quantitative and qualitative differences have been observed. In Fig. 5 for material A with $C_{\mathrm{v}}$ equal to $20 \%$, the flow curves obtained with the two geometric facilities have been reported. At a small shear rate, a minimum in the flow curves attained by the tests carried out using the vane rotor system has been noted: the shear stress decreases with shear rate, followed by a subsequent increase at larger shear rate values. Such behaviour for concentrated suspensions, with a minimum to low shear rate, has been reported by several authors (Nguyen and Boger, 1985; Alderman et al., 1991; Major and Pierson, 1992; Pignon et al., 1996; Coussot, 1997; Ancey and Jorrot, 2001; Kaitna et al., 2007) and only the increasing part of the flow curves has been considered. Moreover, the vane rotor response is higher than the parallel plates response after a shear rate value equal to $501 / \mathrm{s}$. Regardless of the solid volumetric concentrations considered, after this value of shear rate the mixtures analysed behave like a NonNewtonian fluid. In the following, only these experimental results have been analysed.

Probably, some disturbing effects have occurred during the tests like the changing of the material free surface, edge/crack effects, heterogeneities in particle distribution (particle settling and migration due to particle inertia and secondary flow) and the phenomenon of wall slip. The occurrence of some disturbing effects has been evaluated. In static experiments gravity forces are in competition with the Brownian forces. To estimate the sedimentation of the samples of spherical particles, the ratio between gravity (settling) and Brownian forces (thermal) should be greater than 1 (Macosko, 1994):
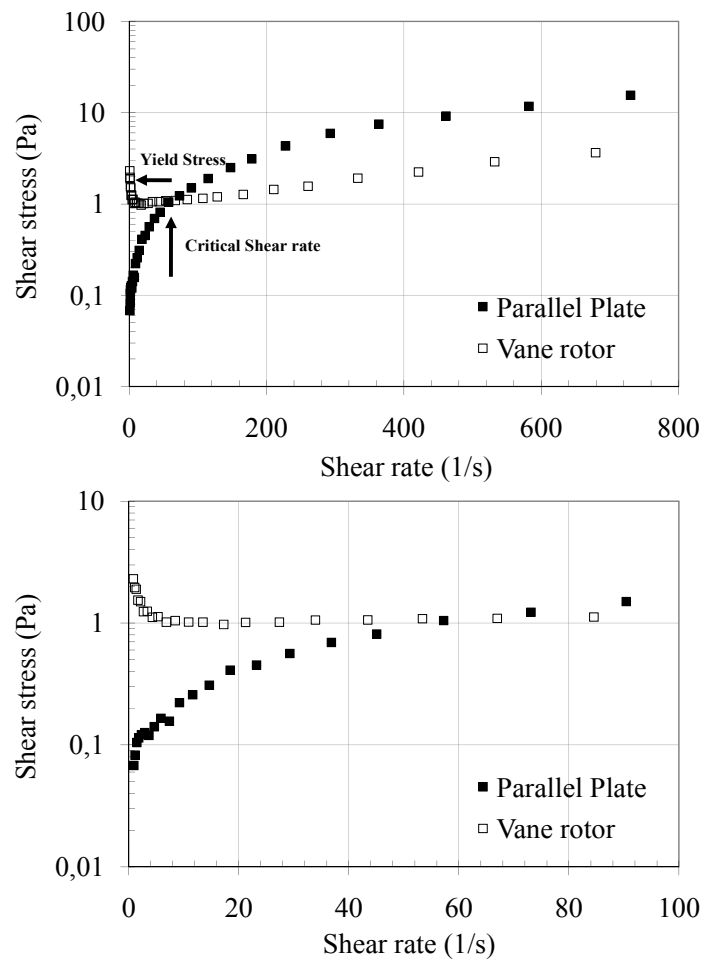

Fig. 5. Material $\mathrm{A}, C_{\mathrm{v}}=20 \%$. Comparison between the experimental results obtained with the parallel plates and the vane rotor system.

$\frac{\text { gravity } \cdot \text { force }}{\text { Brownian } \cdot \text { force }}=\frac{\left(\rho_{\mathrm{d}}-\rho_{\mathrm{c}}\right) \cdot g \cdot a^{3}}{k_{\mathrm{B}} \cdot T / a}$

where $\rho_{\mathrm{d}}$ and $\rho_{\mathrm{c}}$ are the densities of the disperse and continuous phase, $g$ is the acceleration of gravity, $a$ is the particle radius, $k_{\mathrm{B}}$ is the Boltzmann's constant, $T$ is the absolute temperature.

As shown by Larson (1999) sedimentation certainly occurred for $\Delta \rho$, difference between the densities of the disperse $\rho_{\mathrm{d}}$ and the continuous phase $\rho_{\mathrm{c}}$, equal to $10^{3} \mathrm{~kg} \mathrm{~m}^{-3}$ and particles or aggregates larger than $1 \mu \mathrm{m}$ radius. For our mixtures these differences are equal to 1600; the experimental flow condition should be adjusted so that during the experimental time the sedimentation does not play an important role. It is possible to estimate the influence of settling through the calculation of the experimental time $t_{\exp }$ required for a single sphere of radius $a$ to migrate over a length $l(l$ is equal to $H$, the gap height) as in the following:

$t_{\exp }=\frac{9}{2} \cdot \frac{\eta_{\mathrm{c}} \cdot l}{\Delta \rho \cdot g \cdot a^{2}}$

where $\eta_{\mathrm{c}}$ is the viscosity of the continuous phase (for water $\left.10^{-3} \mathrm{~Pa} \mathrm{~s}\right), \Delta \rho$ is the difference between the densities of the disperse $\rho_{\mathrm{d}}$ and the continuous phase $\rho_{\mathrm{c}}, g$ is the acceleration of gravity and $a$ is the radius of the particle with maximum size in the mixtures (Macosko, 1994). For our mixtures this time is equal to $0.115 \mathrm{~s}$ for fine mixtures and equal to $0.005 \mathrm{~s}$ for coarse mixtures. 
Particle inertia can also influence the results of experiments. With the particle Reynolds number $R e_{P}$ an estimation of the inertial effects is possible:

$\operatorname{Re}_{P}=\frac{\rho_{\mathrm{c}} \cdot \dot{\gamma} \cdot a^{2}}{\eta_{\mathrm{c}}}$

In this equation $\dot{\gamma}$ and $\eta_{\mathrm{c}}$ are the shear rate and the viscosity of the continuous phase, respectively. For a maximum diameter used (radius $a$ equal to $0.05 \mathrm{~mm}$ and $0.25 \mathrm{~mm}$ ), and for a shear rate equal to $501 / \mathrm{s}$ particle inertia occurred because the $R e_{P}$ is 0.125 and 3.125 greater than $10^{-1}$ (Macosko, 1994).

In the following, due to the presence of these phenomena, the flow curves for the shear rate more than $501 / \mathrm{s}$ have been shown and interpreted.

\subsection{Experimental results and model fitting}

The flow curves for each analysed material have been reported in Fig. 6. It is noted that all the investigated debris flow mixtures behave like a non-Newtonian fluid and, in particular, like yield stress fluids: shear stress non-linearly increases with the increase of shear rate after a yield stress that represents the value of $\tau$ required to initiate the flow (value of $\tau$ as $\dot{\gamma}$ goes to zero).

The influence of the solid volumetric concentration $C_{\mathrm{v}}$ on the rheological behaviour of fine debris flow material mixtures tested has been evaluated. Proportionally higher values of shear stress with the increasing of the solid volumetric concentration have been noted. Moreover, at equal solid volumetric concentration, the shear stresses of material B are higher than materials $\mathrm{A}$ and $\mathrm{C}$. The rheological parameters of $\mathrm{C}$ mixtures are the lowest due to the different volcanic particle nature (Phelegrean Field) and the higher grain size (Fig. 3b).

The best fitting model of the experimental data is the Bingham generalized (Eq. 1). The theoretical flow curves are reported as a solid line in Fig. 6. Table 3 shows the relative rheological parameters. The obtained yield stress $\tau_{y}$ is plotted versus the solid volumetric concentration $C_{\mathrm{v}}$ in Fig. 7. It can be observed that the yield stress $\tau_{y}$ exponentially increases with the increase of solid volumetric concentration $C_{\mathrm{v}}$. According to some previous study (O'Brien and Julien, 1984, 1988; Phillips and Davies, 1991; Major and Pierson, 1992; Coussot and Piau, 1995; Coussot, 1997; Kaitna et al., 2007), the following relation can be used:

$\tau_{y}=\alpha \cdot e^{\beta \cdot C_{\mathrm{v}}}$

where $\alpha$ and $\beta$ are material parameters. Their values, for all the tested material mixtures, have been reported in Table 4 .

In order to evaluate the influence of larger particles, mixtures with the same solid volumetric concentration and with a maximum diameter of $0.5 \mathrm{~mm}$ were tested using a vane rotor. Figure 8 shows, for instance, the comparison between fine and coarse particle mixtures of the materials $\mathrm{B}$ for a solid volumetric concentration equal to $30 \%$. A decrease of
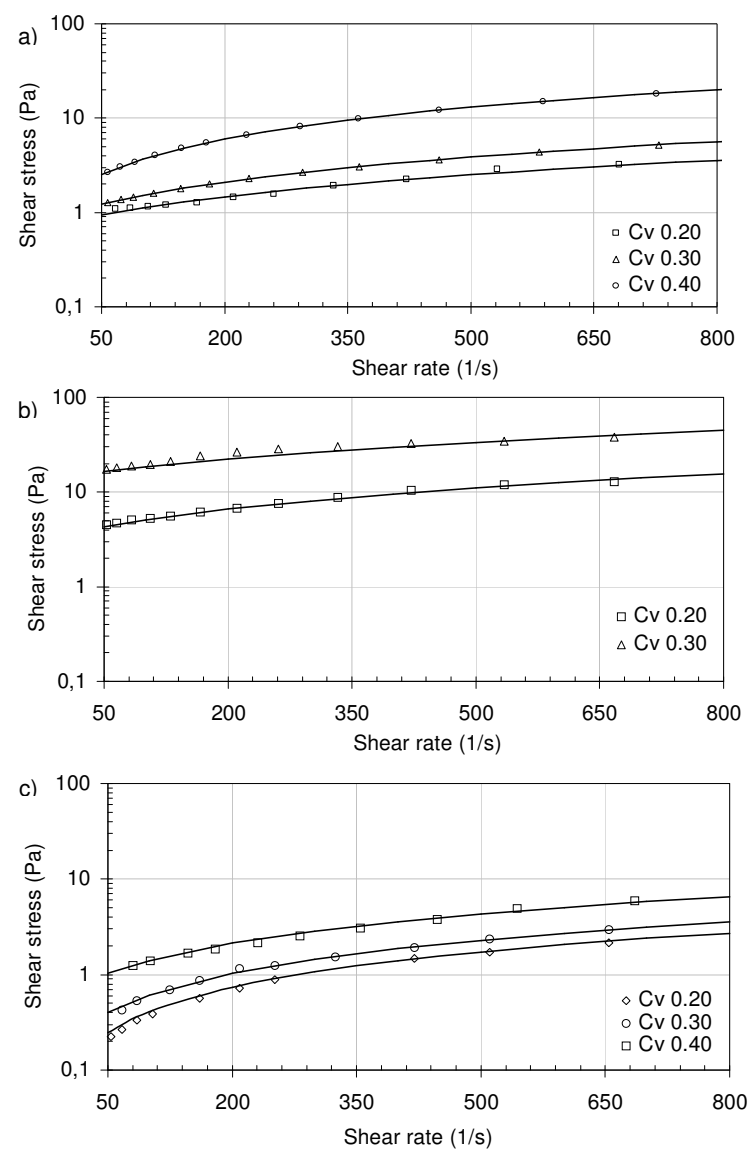

Fig. 6. Experimental data and theoretical flow curves at different volumetric concentration $C_{\mathrm{v}}$ : (a) material A; (b) material B; (c) material C.

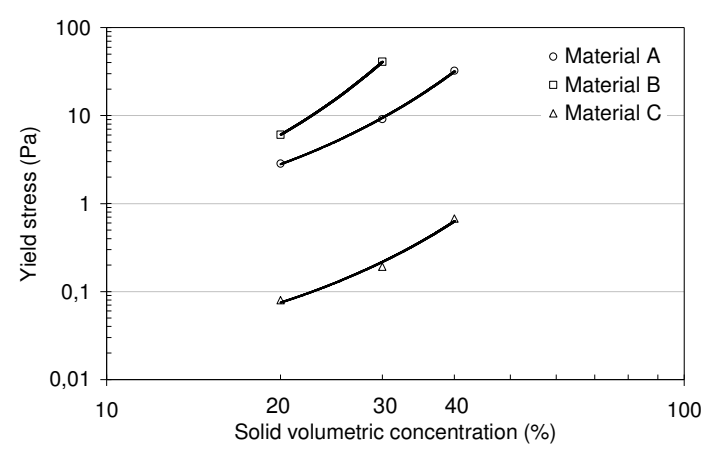

Fig. 7. Yield stress $\tau_{y}$ vs. solid volumetric concentration $C_{\mathrm{v}}$.

yield stress is observed. This reduction may be justified by a decrement of finer content, the yield stress tends to disappear due to a reduction of the fine fraction (clean water).

This behaviour is in agreement with the experimental results of Ancey and Jorrot (2001) on coarse particles within a clay dispersion with a parallel plates system. When the large particle fraction is small compared to the amount of fine particle fraction, the colloidal fine fraction determines the rheological features of the mixture. 
Table 3. Bingham generalized model parameters.

\begin{tabular}{lllrrrr}
\hline Material & $\begin{array}{l}\text { Solid } \\
\text { volumetric } \\
\text { concentration } \\
(\%)\end{array}$ & Mixture & $\begin{array}{r}\text { Yield } \\
\text { stress }\end{array}$ & $\begin{array}{r}\text { Consistent } \\
\text { coefficient }\end{array}$ & $\begin{array}{r}\text { Pseudoplastic } \\
\text { index }\end{array}$ & $\begin{array}{r}\text { Determination } \\
\text { coefficient }\end{array}$ \\
& 20 & Fine particle & 0.4431 & 0.2756 & 0.6116 & $(1)$ \\
\hline A & 30 & Fine particle & 0.9169 & 0.5227 & 0.6116 & 0.988 \\
$\mathrm{~A}$ & 40 & Fine particle & 3.2398 & 2.9569 & 0.6116 & 0.991 \\
$\mathrm{~A}$ & 20 & Fine particle & 3.5465 & 1.8708 & 0.2553 & 0.999 \\
\hline $\mathrm{B}$ & 30 & Fine particle & 14.5960 & 6.7207 & 0.2553 & 0.998 \\
$\mathrm{~B}$ & 30 & Coarse particle & 5.55 & 1.7351 & 0.3653 & 0.955 \\
$\mathrm{~B}$ & 20 & Fine particle & 0.080 & 0.00105 & 0.6842 & \\
\hline $\mathrm{C}$ & 30 & Fine particle & 0.1910 & 0.0914 & 0.6842 & 0.999 \\
$\mathrm{C}$ & 40 & Fine particle & 0.6744 & 0.2302 & 0.6842 & 0.999 \\
$\mathrm{C}$ & & & & & & \\
\hline
\end{tabular}

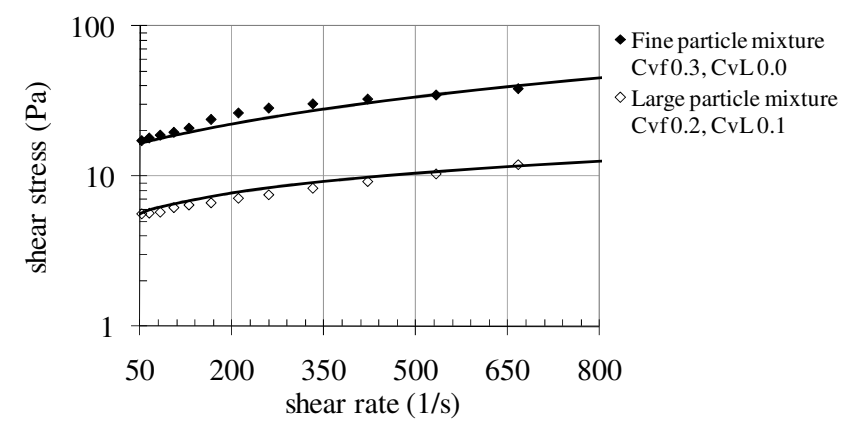

Fig. 8. Material B: effect of maximum particle diameter for $C_{\mathrm{V}}$ equal to $30 \%$.

Instead, as observed in different studies led using nonconventional rheometers on material mixtures, rheological properties are altered by addiction of larger particles (up to several centimeters) to the viscous fluid (Coussot and Piau, 1995; Contreras and Davies, 2000; Schatzmann 2005). Thus, rheological parameters determined by debris flow material of limited grain size with a conventional rheometer do not represent the bulk rheological behaviour of the complete natural material. Therefore, further tests are necessary on mixtures including sand and gravel fraction according to the natural grain size distribution. This activity is being undertaken through the development of a new type of equipment that is presently being tested.

\section{Conclusions}

In order to evaluate the rheological behaviour of debris-flow material, laboratory tests involving soils taken in the source areas of three debris flows occurred in Campania region (southern Italy) were carried out. Mixtures with varying concentration of fine sediment with maximum diameter less than $0.1 \mathrm{~mm}$ (fine particle mixture) and less than $0.5 \mathrm{~mm}$ (coarse
Table 4. Material parameters.

\begin{tabular}{lcc}
\hline Material & $\alpha$ & $\beta$ \\
\hline A & 0.2464 & 0.1215 \\
B & 0.1333 & 0.1909 \\
C & 0.0089 & 0.1066 \\
\hline
\end{tabular}

particle mixtures), and distilled water were prepared. Such mixtures were investigated in a standard rheometer with two different geometries, the parallel plates system and the vane rotor system, in order to distinguish disturbing effects. The vane geometry seems to be an appropriate rheometrical tool for quantitative evaluation of the rheological behaviour of debris flow materials. Instead, by using the parallel plates system, only some qualitative ideas about their behaviour can be obtained. The comparison between the results of the two geometry configurations allows checking the range of shear rate where there are no disturbing effects and misleading evaluations. In this range of shear rate all the tested debris flow mixtures behave like a non-Newtonian fluid with a yield stress $\tau_{y}$ that increases with solid volumetric concentration $C_{\mathrm{v}}$ and decreases for sand fraction increase. The experimental data were fitted with the theoretical Bingham generalized model, in the range of the evaluated shear rate. A simple relation between $C_{\mathrm{v}}$ and $\tau_{y}$ was obtained.

These results suggest that in the field a small change in solid fraction, due to rainfall, will cause a slight decrease of the yield stress, inducing a flow rapidly reaching a shear rate larger than the critical shear rate associated with a rapid flow. Then, the flow will stop only when the material reaches a much smoother slope. This might explain the in situ observed post-failure behaviour of debris flows, which are able to flow over very long distances even over smooth slopes.

The rheological parameters determined for flows of limited grain size with a conventional rheometer do not represent 
the bulk rheological behaviour of the complete natural material. Further tests are necessary on mixtures including sand and gravel fraction reflecting the natural grain size distribution. This activity is being undertaken through the development of a new equipment under test. The yield stress seems to be a key parameter for describing and predicting the postfailure behaviour of debris flows, but further experimental validation is required.

Acknowledgements. We thank Renzo Pepi for assisting in carrying out rheometer tests at the Dept. of Chemical Science and Technology and Biosystems, University of Siena and the TA Instruments for having lent the Rheometer AR 2000EX.

Edited by: G. G. R. Iovine

Reviewed by: A. Bartosik and two anonymous referees

\section{References}

Alderman, N. J., Meeten, G. H., and Sherwood, J. D.: Vane rheometry of bentonite gels, J. Non-Newton. Fluid. 39, 291-310, 1991.

Ancey, C. and Jorrot, H.: Yield stress for particle suspensions within a clay dispersion, J. Rheol., 45(2), 297-319, 2001.

Bagnold, R. A.: Experiment on a gravity-free dispersion of large solid sphere in a Newtonian fluid under shear, Proc. of The Royal Society London, Series A, 49-63, 1954.

Chhabra, R. P. and Richardson, J. F.: Non-Newtonian Flow in the Process Industries, Butterworth-Heinemann, Oxford, 436 pp., 1999.

Contreras, S. M. and Davies, T. H. R.: Coarse-Grained Debris Flows, Hysteresis and Time-Dependent Rheology, J. Hydraul. Eng.-Asce, 126, 938-941, 2000.

Costa, J. E. and Williams, G. P.: Debris flow dynamics (videotape), US Geological Survey Open file 84-606, $22 \mathrm{~min}$, available at: http://www.pubs.usgs.gov/of/1984/ofr84-606/, 1984.

Coussot, P. and Piau, J. M.: On the behaviour of fine mud suspensions, Rheol. Acta, 33, 175-184, 1994.

Coussot, P. and Piau, J. M.: A large-scale field cylinder rheometer for the study of the rheology of natural coarse suspensions, J. Rheol., 39(1), 105-123, 1995.

Coussot, P.: Mudflow Rheology and Dynamics, IAHR Monograph Series, A. A. Balkema, Rotterdam, 1997.

di Gennaro, A., Terribile, F., Basile, A., Aronne, G., Buonanno, M., De Mascellis, R., and Vingiani, S.: I suoli delle aree di crisi di Quindici e Sarno: proprietà e comportamenti in relazione ai fenomeni franosi, $2^{\circ}$ Rapporto informativo dell'Unità Operativa $4.21 \mathrm{~N}$ del C.N.R. - G.N.D.C.I., L'instabilità delle coltri piroclastiche delle dorsali carbonati che in Campania, Primi risulatati di uno studio interdisciplinare, 1998.

Iverson, R. M.: The physic of debris flow, Rev. Geophys., 35, 245296, 1997.

Johnson, A. M.: Debris flow, Topics in Slope Instability, edited by: Brunsdenm, D. and Prior, D. B., Wiley, New York, 257-361, 1984.

Kaitna, R., Rickenmann, D., and Schatzmann, M.: Experimental study on rheological behaviour of debris flow material, Acta Geotech., 2, 71-85, 2007.

Larson, R. G.: The Structure and Rheology of Complex Fluids, Oxford Univ. Press, New York, 1999.
Major, J. J. and Pierson, T. C.: Debris flow rheology: experimental analysis of fine - grained slurries, Water Resour. Res., 28(3), 841-857, 1992.

Macosko, C. W.: Rheology. Principles, Measurements and Applications, Wiley-VCH, Inc., 1994.

Nguyen, Q. D. and Boger, D. V.: Direct yield stress measurement with the vane method, J. Rheol., 29, 335-347, 1985.

Nguyen, Q. D. and Boger, D. V.: Measuring the flow properties of yield stress fluids, Annu. Rev. Fluid Mech., 24, 47-88, 1992.

O'Brien, J. S. and Julien, P. Y.: Physical properties and mechanics of hyperconcentrated sediment flow: Proc. of the Specialty Conference on Delineation of landslide, flash flood and debris flow hazard in Utah, Utah Water Research Laboratory, General Series, UWRL/G-85/03, 260-278, 1984.

O'Brien, J. S. and Julien, P. Y.: Laboratory analysis on mudflow properties, J. Hydraul. Eng.-Asce, 144, 877-887, 1988.

Papa, R.: Indagine sperimentale di una copertura piroclastica di un versante della Campania, $\mathrm{PhD}$ thesis, University of Naples "Federico II", 2007.

Phillips, C. J. and Davies, T. R. H.: Determining rheological parameters of debris flow material, Geomorphology, 4, 573-587, 1991.

Picarelli, L., Evangelista, A., Rolandi, G., Paone, A., Nicotera, M. V., Olivares, L., Scotto di Santolo, A., Lampitiello, S., and Rolandi, M.: Mechanical properties of soils in Campania Region. Proc. Int. Int. Workshop on Characterisation \& Engineering Properties of Natural Soils, edited by: Tan, Phoon, Hight and Leroueil, Singapore, 29 November-1 December 2006, Taylor \& Francis Group, London, 4, 2331-2383, 2007.

Pignon, F., Magnin, A., and Piau, J. M.: Thixotropic colloidal suspension and flow curve with a minimum: identification of flow regimes and rheometric consequence, J. Rheol., 40, 573-587, 1996.

Ruopolo, S.: Analisi dei fenomeni franosi nella coltre piroclastica non satura del cratere degli Astroni, Graduate thesis, Department of Geotechnical Engineering, University of Naples "Federico II", 2006.

Savage, S. B. and Hutter, K.: The motion of a finite mass of granular material down a rough incline, J. Fluid Mech., 199, 177-215, 1989.

Schatzmann, M.: Rheometry of large particle fluids and debris flows, PhD Dissertation No 16093, ETH, Zürich, Switzerland, 2005.

Scotto di Santolo, A.: Analisi geotecnica dei fenomeni franosi nelle coltri piroclastiche della provincia di Napoli, $\mathrm{PhD}$ thesis, University of Naples "Federico II" and Rome "La Sapienza", 2000a.

Scotto di Santolo, A.: Analysis of a steep slope in unsaturated soils. Proc. Asian Conference on Unsaturated Soils, Singapore, Balkema, Rotterdam, 569-574, 2000b.

Scotto di Santolo, A. and Evangelista, A.: Some observations on the prediction of the dynamic parameters of debris flows in deposits in the Campania region of Italy. Int., J. Nat. Hazards, 50, 605622, 2009.

Takahashi, T.: Debris flow Mechanics, Prediction and Countermeasures, Taylor and Francis Group, London, 35-38, 2007. 